\title{
A hybrid approach for measuring of the consumer preferences
}

\author{
José Nilton Martini ${ }^{a}$, Fernando Antônio Forcellini ${ }^{b}$ \\ Universidade do Estado de Santa Catarina \\ e-mail: jose.martini@udesc.br \\ UUniversidade Federal de Santa Catarina \\ e-mail: fernando.forcellini@ufsc.br
}

\begin{abstract}
The knowledge of the consumers preferences is indispensable so that one may successfully define the configurations of new products. Therefore, before defining the attributes of new products, consumers must be consulted and their preferences measured. Among the alternatives for measuring of the consumers preferences there are the hybrid approaches that combine compositive and de-compositive portions of measurement. In this paper is presented a hybrid approach of measurement, formulated, initially, to bypass difficulties found in adopting traditional hybrid procedures. With the proposed approach, there is no need of supporting equipment or ordination of configurations by consumers during measurement, typical of the approaches frequently employed. The proposed measurement approach is presented through an example of measurement of the preferences of the potential consumers of electric portable devices. The attributes of the products and their levels are chosen to describe the products of the chosen market segment, as well the configurations for comparison. The construction of the measurement form of consumer preferences is shown throughout the article. One also presents the survey and treatment of the information of preferences, as well as the partial uses of the attributes from measurement. The measurement approach proposed in this paper has shown itself applicable and its employment results in an information base containing consumer preferences very useful to the definition of the configurations of new products. In this paper, as an illustration, the consumer preferences information are employed in the definition of 'ideal' configurations of electric mini-ovens for the preferences of a consumer that represents the average of the individuals surveyed.
\end{abstract}

Keywords: consumer preferences, hybrid approach for measurement, attributes, configurations.

\section{Introduction}

According to Tessarolo (2004), it is on the basis of the difference of utility between the configurations available in the market that consumers define which product to acquire. Utility can be defined as the psychological satisfaction from the purchase of the products (MARKETING..., 2008). The product acquisition process, considering the utility difference between them, can be schematized in three steps:

- Comparative analysis of the offer and highlight of the differences between the products;

- Estimation of utility of each product based on the differences between them; and

- Choice of product with maximum utility.

The utility of a given product can be obtained by the composition of the utilities of its attributes (and levels). By attribute one understands the characteristics that are present in the products to attract consumers (MARKETING..., 2008). In the additive model, which is illustrated by the expression (1), one composes the utility of the product by summing up the utilities of its attributes. In this expression, $U x$ is the utility of the $x$-eth configuration of the product and uij is the utility of the $j$-eth level of the $i$-eth attribute present in the evaluated configuration.

$$
U_{x}=\sum u \text { ij }
$$

The companies that manage to measure the utility of the levels of the possible attributes put themselves in the privileged position of projecting and developing the products that result in the maximum satisfaction of consumers (TESSAROLO, 2004). Therefore, the knowledge of the potential utilities of the various possible configurations of the products (their attributes and levels) for prospects is fundamental for the development of success products.

The simplest way to measure consumers' preferences is the direct approach. In this approach, however, consumers usually choose the best-known marks, the better-performing products, the lower prices and interest rates, and so on, resulting in little relevant information for the development of new products. In the face of this reality, structured forms of measuring consumers' preferences have been developed, which can be classified according to three approaches (GREEN; SRINIVASAN, 1990). The first one is called compositional approach. The second one is the de-compositional approach, represented by Joint Analysis. The third way combines both compositional and 
de-compositional approaches for surveying consumers' preferences and is called hybrid approach.

In the compositional approach one asks consumers to comparatively evaluate the several levels of attributes of the products. From this evaluation one can estimate the utilities of these attributes that will later be utilized to compose the utility of a product in particular (obtained by the sum of the utilities of the attributes present in the configuration). In the de-composition approach consumers comparatively evaluate several alternatives of configurations of products (formed of certain attributes) and from this evaluation the utilities of the attributes are obtained, which are utilized later for the calculation of the utility of a specific variant of the product. The hybrid approach, as already mentioned, utilizes the measurements of the utility of the attributes that have been obtained in both compositional and de-compositional manners.

From mid-1970, a number of papers on the application of de-compositional hybrid approaches to the development of new products have been published in specialized literature. Among the several works published, some have been chosen and are quoted as follows to illustrate the reach of the applications involving the use of these approaches. Sands and Warwick (1986) define the characteristics of a table radio from the Joint Analysis for a market segment. Lakshmikantha et al. (2005) define the physical attributes of the rear-vision mirror of an auto-rickshaw with this tool. Dove and Bachelder (1990) apply the Joint Analysis to find the relative importance given by consumers to the electronic banking services. Miller et al. (1998) evaluate the sensitivity to price and value of the characteristics of the calls of a telephone operator. Yamamoto and Lambert (1994) study the importance of aesthetics in the evaluation of the industrial products helped by the de-composition of consumers' preferences. Nagle, Holdem e Zale (2006) show how the characteristics of a hotel have been defined from a segmented Joint Analysis.

There are advantages and disadvantages in using a particular approach for measuring consumers' preferences. The compositional approach offers a quick alternative to the measurement of the preferences, however, its accuracy is lower than the other alternatives. The complete Joint Analysis is the most accurate of the measurements, but, on the other hand, it requires the ordination of a very great number of product configuration alternatives (many times making their application unfeasible). The simplified Joint Analysis is a commitment approach between the speed and the accuracy of the measurement of consumers' preferences. The hybrid approaches are also commitment alternatives between the speed and accuracy of the measurement. For utilizing a compositional basis in the estimation of the partial utilities, therefore, more conservative approaches, they are less susceptible to big deviances (residue between the measured and the estimated utility). The measurement alternatives of hybrid consumers' preferences, however, have some characteristics that prevent their use without previous questionings. In the Hybrid Joint Analysis, for example, there is the need of an ordination of a sometimes extensive set of product configuration alternatives. In the Adaptative Joint Analysis, due to its interactive characteristic, the research cannot be previously defined, making its application difficult without the help of computers. To work around these disadvantages of measurement approaches, one suggests in this work an original alternative of hybrid measurement of consumers' preferences presented in the next sections.

\section{Measurement approach}

The approach proposed for measuring consumers' preferences utilizes a compositional database combined with a set of product configuration evaluations in pairs. The measurement approach formulated in this work is composed of 5 steps, many of them common to hybrid approaches. The first step is the definition of the attributes and their levels, which must describe both the configurations of the competing products and the potential configurations of products of their own. Next, one chooses the configurations for comparison of complete product profiles. Once known the attributes, their levels for comparison of the products to the pairs, one can build the measurement form. The following steps are the measurement of the preferences of the potential consumers and the treatment of this information.

\section{Choice of attributes and their levels for describing the products}

To illustrate the approach proposed in this paper, one proposes the measurement of the preferences of a group of potential consumers to define the ideal configuration of an electric mini-oven. In this application example, a nonexisting mark of electric mini-ovens (Hot) is utilized as a configuration alternative against marks already present in the market. To employ the proposed measurement procedure, one must know the configurations of the products available in the market and how they can be described through a set of attributes and their levels. From the attributes of the products available in the market one defines the levels of the attributes employed in the description of both the competing products and the potential products of their own. The description of the potential products of this market segment permits the execution of measurement of consumers' preferences. The attributes considered as important to describe and differentiate the electric mini-ovens are:

- Mark: product manufacturer's name;

- Approximate price in practice in retail; 
- Capacity: oven volume;

- Heating control: oven heating options;

- Timer: cooking time programming with a sound notice;

- Potency: energy supply capacity for cooking;

- Display: screen to show information on timer and oven heating (this attribute is not present in any configuration of competing products and has been added to the list of attributes as a differential of the electric mini-ovens of the mark Hot);

- Predominant color of oven;

- Layout: spatial disposition of the main elements of the oven (controls and ovens put side by side and controls under the oven); and

- Door opening: vertical or horizontal axis.

The characteristics of the mini-ovens of the mark Hot have been limited. The electric mini-ovens that have been considered as competitors share the following characteristics:

- The price for consumers is smaller than $\mathrm{R} \$ 250.00$;

- The products available for purchase, but discontinued by the manufacturers, have been disregarded;

- Products of little known marks which are not easily found do not form part of this example; and

- The sale prices admitted are approximations of the prices in reais found at the shops.

One has found 7 mini-ovens with the characteristics mentioned in the previous section. These mini-ovens are of 6 different marks. The description of these mini-ovens according to the attributes considered in this application example is presented in Table 1.

For each of the attributes chosen in this application example, their alternative levels are identified so that all the products can be described. For the Mark attribute, for example, the products can take on 7 different levels: 6 levels for each of the marks found in the market and 1 level for the mark of the company which is configuring its products. The 6 marks present in the market (admitted in this example) are shown in Table 2 (Arno, Black \& Decker, Britânia, Cadence, Suggar, and Walita). The mark whose products one wished to configure will be called Hot in this example. The admitted price levels to consumers are 6 , starting at $\mathrm{R} \$ 100.00$ and ending at $\mathrm{R} \$ 225.00$, with intervals of $\mathrm{R} \$ 25.00$ between the levels. Three capacity levels are considered: 7, 8 or 9 liters. The potency of the ovens can take on alternative levels: 650 , 850 or 1050 Watts. The mini-oven color can vary in 4 levels. Three levels correspond to the usual colors made available by the manufacturers to consumers: white, black, and silver. A level is reversed for measuring the utility of a colored mini-oven (red) for consumers. The heating control, the timer and the display can take on 2 levels: present or absent (the timer is present in all the competing products and the display is present in none). Finally the layout of the products and the opening axis of the oven door are also considered for the evaluation of consumers. Two layout alternatives are considered: vertical and horizontal. In the vertical layout the oven volume is put on the controls and in the horizontal layout the oven volume is beside the controls. The oven door

Table 1. Description of competing electric mini-ovens.

\begin{tabular}{|c|c|c|c|c|c|c|c|c|c|}
\hline Mark & $\begin{array}{c}\text { Price } \\
\text { [Reais] }\end{array}$ & $\begin{array}{c}\text { Capacity } \\
\text { [liters] }\end{array}$ & $\begin{array}{l}\text { Heating } \\
\text { control }\end{array}$ & $\begin{array}{c}\text { Timer with } \\
\text { audible } \\
\text { warning }\end{array}$ & $\begin{array}{l}\text { Potency } \\
\text { [Watts] }\end{array}$ & Display & Color & Layout & $\begin{array}{c}\text { Door } \\
\text { opening } \\
\text { [axis] }\end{array}$ \\
\hline Arno (Forma) & 175.00 & 8 & present & present & 800 & absent & silver & vertical & horizontal \\
\hline B\&D (FE500) & 170.00 & 8 & present & present & 650 & absent & black & horizontal & horizontal \\
\hline Britânia (9L) & 160.00 & 9 & present & present & 800 & absent & silver & horizontal & horizontal \\
\hline Cadence (For750) & 100.00 & 7 & absent & present & 650 & absent & black & horizontal & horizontal \\
\hline Suggar (8L) & 100.00 & 8 & present & present & 700 & absent & white & horizontal & horizontal \\
\hline Walita (RI4493) & 170.00 & 9 & absent & present & 820 & absent & silver & vertical & horizontal \\
\hline Walita (RI4495) & 225.00 & 9 & present & present & 1100 & absent & silver & vertical & horizontal \\
\hline
\end{tabular}

Table 2. Levels of attributes of the products for the example of measurement of the preferences.

\begin{tabular}{|c|c|c|c|c|c|c|c|c|c|c|}
\hline \begin{tabular}{|c|}
$\begin{array}{c}\text { Atributtes/ } \\
\text { levels }\end{array}$ \\
\end{tabular} & Mark & $\begin{array}{c}\text { Price } \\
\text { [Reais] }\end{array}$ & $\begin{array}{l}\text { Capacity } \\
\text { [liters] }\end{array}$ & $\begin{array}{l}\text { Heating } \\
\text { control }\end{array}$ & $\begin{array}{c}\text { Timer with } \\
\text { audible } \\
\text { warning }\end{array}$ & $\begin{array}{l}\text { Potency } \\
\text { [Watts] }\end{array}$ & Display & Color & Layout & $\begin{array}{c}\text { Door } \\
\text { opening } \\
\text { [axis] } \\
\end{array}$ \\
\hline 1 & Arno & 100.00 & 7 & present & present & 650 & present & white & horizontal & horizontal \\
\hline 2 & $B \& D$ & 125.00 & 8 & absent & absent & 850 & absent & black & vertical & vertical \\
\hline 3 & Britânia & 150.00 & 9 & --- & --- & 1050 & --- & silver & --- & --- \\
\hline 4 & Cadence & 175.00 & --- & --- & --- & --- & --- & red & --- & --- \\
\hline 5 & Hot & 200.00 & --- & --- & --- & --- & --- & --- & --- & --- \\
\hline 6 & Suggar & 225.00 & --- & --- & --- & --- & --- & --- & --- & --- \\
\hline 7 & Walita & --- & --- & --- & --- & --- & --- & --- & --- & --- \\
\hline
\end{tabular}


opening is also evaluated in 2 levels. One considers two possibilities for the door to be opened: horizontal opening axis (as in the traditional ovens) or vertical axis (as usually made available in the microwave ovens). The Table 2 gathers the levels adopted for each of the attributes utilized in the example of measurement of consumers' preferences.

\section{Comparisons between complete product profiles}

Once chosen the attributes and their levels, the following step is to define the number of comparisons between complete product profiles and which configurations will be utilized in the comparison. The number of configurations for comparison must be defined not to burden too much the interviewees' time. In the Hybrid Joint Analysis (de-compositive portion) one proposes that no more than 8 or 9 configurations for ordination be utilized. By utilizing this proposal as reference, one has chosen to utilize 7 comparisons between configurations in the application - therefore, 14 distinct configurations must be chosen (twice as much the number of levels of the attribute with more levels). The 14 configurations of products for comparison have been chosen in a way that they should form an orthogonalized set (the smallest sum of the internal product between the vectors representing the configurations) and are presented in the Table 3. In this frame, each line is a product configuration and each column represents an attribute. That is, number $x$ present in column $y$ of line $z$ of the Table 3 represents the presence of level $x$ of attribute $y$ in the configuration of product $z$.

The 14 configurations indicated in Table 3 are presented, during the measurement of the preferences, in pairs for comparison of their utilities by potential consumers. The configuration pairs are chosen so that one minimizes the levels of the common attributes. According to this premise, one can, by inspection, obtain the 7 configuration pairs for comparison shown in Figure 1.

\section{Research form}

Once defined the attributes, their levels, the complete profiles, and the pairs for comparison, one can build the research form. The form for surveying consumers' preferences, according to the proposed approach, has two parts. The first part is utilized for measuring the preferences according to the composition approach. The second part is for measuring the preferences according to the de-composition approach. For the compositional portion, one has a frame in which are described the attributes and their levels, Figure 2. In the second part, de-composition portion, one presents 7 comparisons suggested between complete profiles of products utilized for 'calibrating' the utilities computed by the compositional approach. The complete profiles for comparison are presented to potential consumers in a graphic and textual form, as can be seen in Figures 3 and 4 .

\begin{tabular}{|c}
\hline $\begin{array}{c}\text { Configuration pairs of } \\
\text { products for comparison }\end{array}$ \\
\hline M X F \\
\hline GX K \\
\hline IXE \\
\hline B X L \\
\hline CX H \\
\hline JXN \\
\hline AX D \\
\hline
\end{tabular}

Figure 1. Configuration pairs of products for comparison.

Table 3. Orthogonalized configurations for comparison.

\begin{tabular}{|c|c|c|c|c|c|c|c|c|c|c|}
\hline \multirow{2}{*}{$\begin{array}{c}\text { Configuration } \\
\text { A } \\
\end{array}$} & \multicolumn{10}{|c|}{ Levels of attributes } \\
\hline & 1 & 6 & 3 & 1 & 2 & 2 & 2 & 2 & 2 & 2 \\
\hline $\mathrm{B}$ & 2 & 3 & 2 & 2 & 1 & 1 & 1 & 2 & 1 & 2 \\
\hline $\mathrm{C}$ & 4 & 4 & 1 & 2 & 2 & 3 & 2 & 3 & 2 & 1 \\
\hline $\mathrm{D}$ & 5 & 2 & 1 & 2 & 1 & 2 & 2 & 1 & 1 & 1 \\
\hline $\mathrm{E}$ & 7 & 5 & 2 & 1 & 2 & 1 & 1 & 4 & 1 & 2 \\
\hline $\mathrm{F}$ & 7 & 2 & 3 & 1 & 1 & 3 & 1 & 2 & 2 & 2 \\
\hline $\mathrm{G}$ & 6 & 5 & 3 & 2 & 1 & 2 & 2 & 4 & 1 & 2 \\
\hline $\mathrm{H}$ & 2 & 5 & 2 & 1 & 1 & 1 & 2 & 1 & 2 & 2 \\
\hline $\mathrm{I}$ & 3 & 4 & 3 & 2 & 1 & 3 & 1 & 3 & 2 & 1 \\
\hline $\mathrm{J}$ & 1 & 1 & 3 & 2 & 1 & 1 & 1 & 3 & 1 & 2 \\
\hline $\mathrm{K}$ & 4 & 1 & 2 & 1 & 2 & 2 & 1 & 4 & 2 & 1 \\
\hline $\mathrm{L}$ & 3 & 6 & 1 & 1 & 2 & 2 & 1 & 4 & 2 & 1 \\
\hline $\mathrm{M}$ & 6 & 3 & 1 & 2 & 2 & 1 & 1 & 1 & 1 & 1 \\
\hline $\mathrm{N}$ & 5 & 6 & 1 & 1 & 2 & 3 & 2 & 2 & 1 & 1 \\
\hline
\end{tabular}




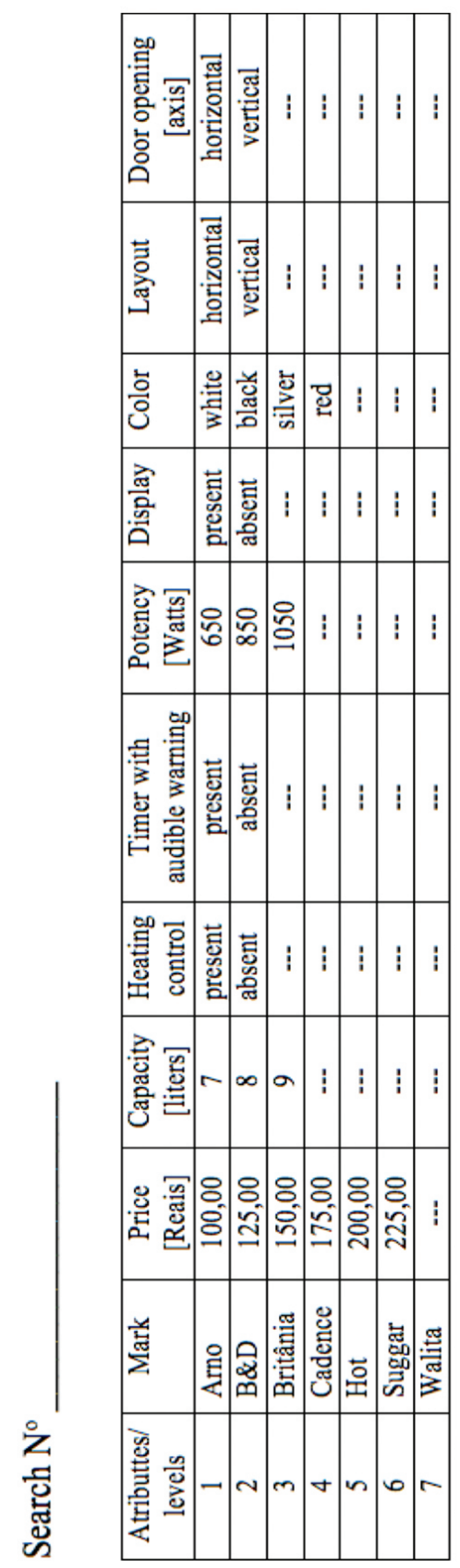

Figure 2. Form for compositive evaluation of partial utilities

\section{Survey of preferences - compositive portion}

The hybrid approach adopted in this application example is initiated by the survey of consumers' preferences in a compositional way, that is, a direct survey of the parties' utilities. The procedure adopted for this survey presents to the potential consumer the attributes of the products and their levels. Initially, utilizing a scale that varies from 1 to 10 , one asks the potential consumer to evaluate each of the attributes of the products. The attribute of greatest importance for this consumer must receive weight 10 and

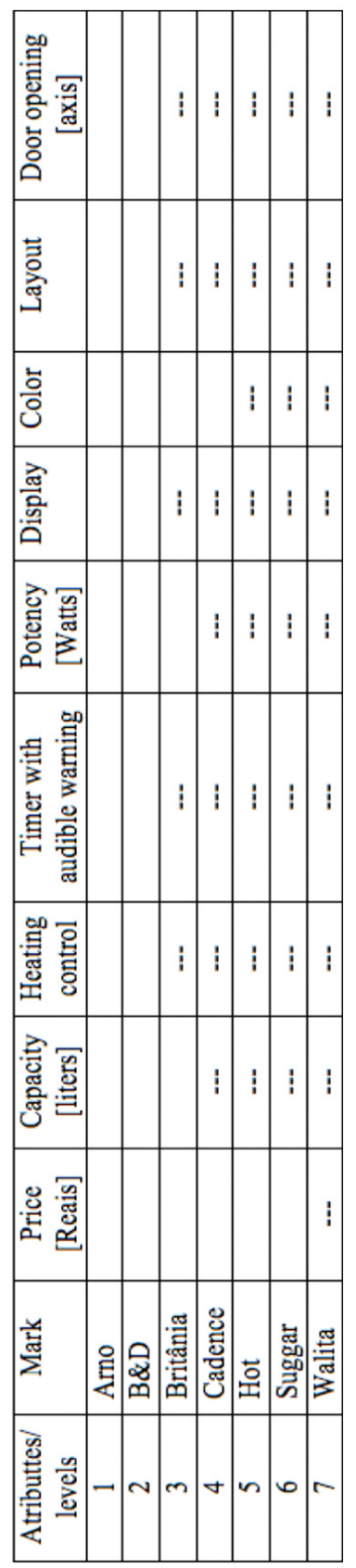

the attribute of smallest importance must receive weight 1 . The other attributes must receive weights between these limits. Two, or more, attributes can receive the same weight. The Table 4 illustrates in its first line the attribution of the weights of the attributes, according to the procedure described, of a potential consumer researched.

An identical procedure is followed for the survey of the preferences between the levels of each of the attributes. The level that the potential consumer considers as more important must receive weight 10 , the level considered as less important must receive weight 1 , and the other levels 


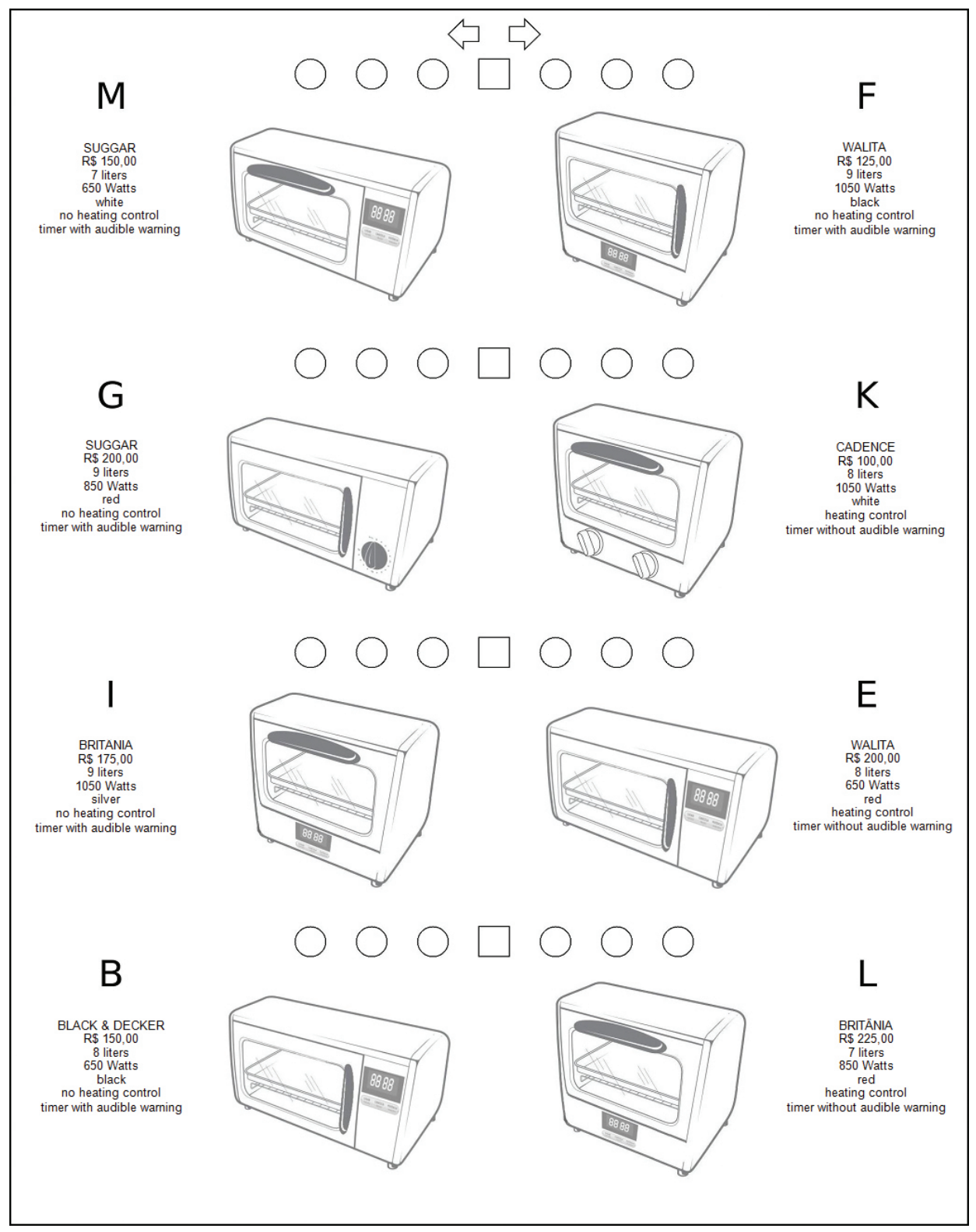

Figure 3. First part of the form for de-compositive evaluation. Illustrations derived from the electric mini-oven model Britânia.

must receive weights between these limits (again 2, or more, levels can have the same weights). The frame of Table 4 shows the weights marked by a potential consumer researched for the levels of the attributes considered in this example.

The first step in the treatment of the information obtained from consumers is the multiplication of the weights of the attributes by the weights of their levels, which results in a relative measure of the partial utilities for a given consumer. The following step of the compositional portions of the hybrid approach is the normalization of the partial utilities. One presupposes that the normalization is such that the configuration of the product of greatest utility for a given consumer equals 4 . This proposal is due to the adoption of a scale for the comparison of 2.25-background configurations, which will be presented ahead. The proposed normalization can be calculated by expressions (2) and (3). In expression (2), Umax is the maximum total utility between the possible configurations of the products, $N A$ is the total number of attributes employed in the measurement, and $P A i$ is the weight given to attribute $i$ by the consumer. In the expression (3), uij is the partial, compositional, normalized utility of level $i$ of attribute $j$, and PNiAj is the weight of level $\mathrm{i}$ of attribute $j$ (weights illustrated in Table 4).

$$
\begin{aligned}
& U_{\max }=10 \sum_{i=1}^{N A} P_{A i} \\
& u_{i j}=\frac{4 \cdot P_{A i} \cdot P_{N i A i}}{U_{\max }}
\end{aligned}
$$




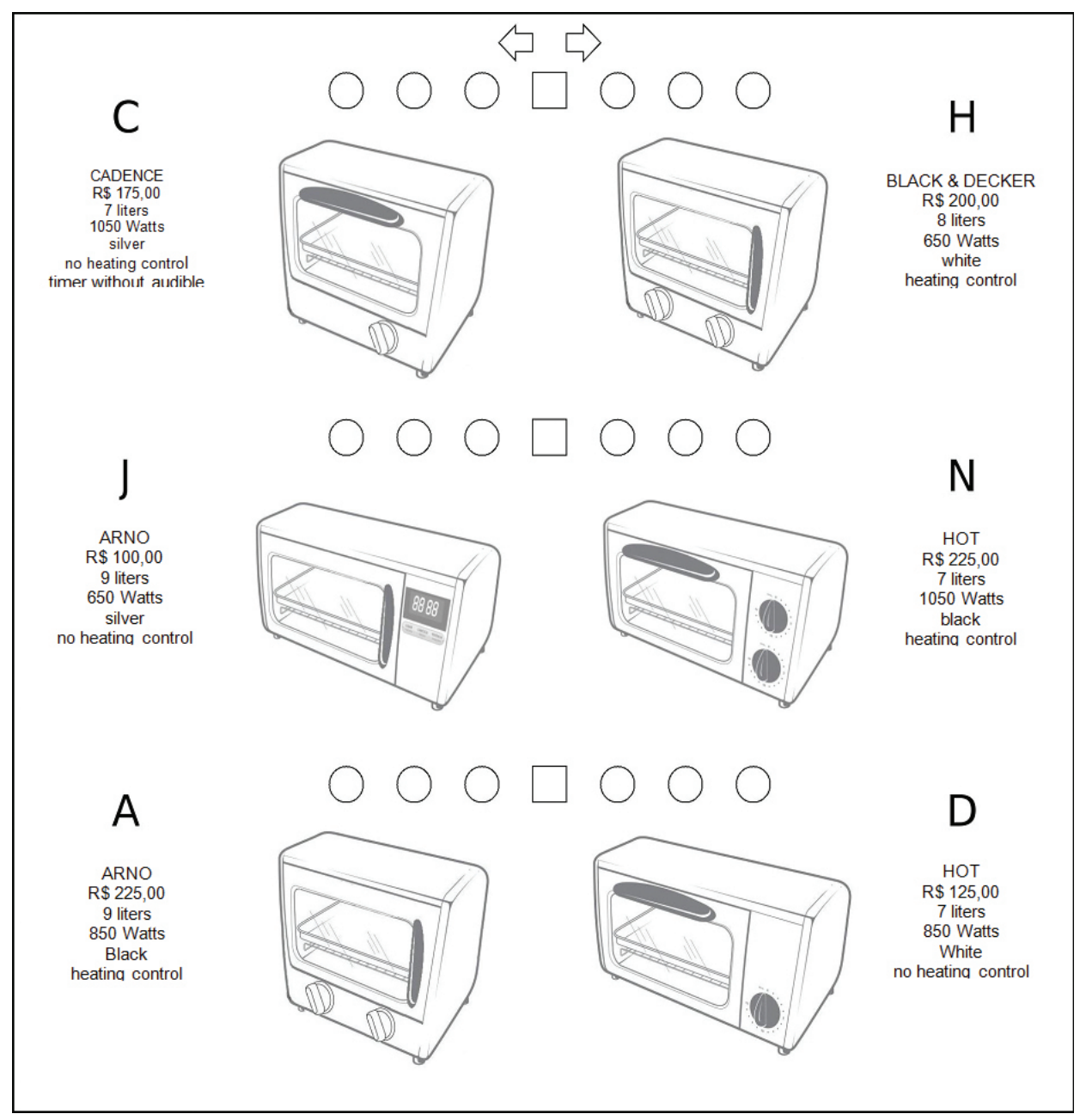

Figure 4. Second part of the form for de-compositive evaluation.

Table 4. Weights of the attributes and their levels according to a potential consumer.

\begin{tabular}{|c|c|c|c|c|c|c|c|c|c|c|}
\hline Weight & $\mathbf{7}$ & $\mathbf{1 0}$ & $\mathbf{2}$ & $\mathbf{4}$ & $\mathbf{4}$ & $\mathbf{6}$ & $\mathbf{4}$ & $\mathbf{3}$ & $\mathbf{3}$ & $\mathbf{1}$ \\
\hline $\begin{array}{c}\text { Attribu- } \\
\text { tes/ levels }\end{array}$ & Mark & $\begin{array}{c}\text { Price } \\
\text { [Reais] }\end{array}$ & $\begin{array}{c}\text { Capacity } \\
\text { [liters] }\end{array}$ & $\begin{array}{c}\text { Heating } \\
\text { control }\end{array}$ & $\begin{array}{c}\text { Timer with } \\
\text { audible } \\
\text { warning }\end{array}$ & $\begin{array}{c}\text { Potency } \\
\text { [Watts] }\end{array}$ & Display & Color & $\begin{array}{c}\text { Layout } \\
\text { Door } \\
\text { opening } \\
\text { [axis] }\end{array}$ \\
\hline 1 & 8 & 10 & 1 & 10 & 10 & 1 & 1 & 1 & 1 & 1 \\
\hline 2 & 10 & 8 & 10 & 1 & 1 & 6 & --- & 10 & 10 & 10 \\
\hline 3 & 5 & 6 & 7 & --- & --- & 10 & --- & 8 & -- & --- \\
\hline 4 & 5 & 4 & --- & --- & --- & --- & --- & 5 & -- & --- \\
\hline 5 & 1 & 2 & --- & --- & --- & --- & --- & -- & -- & --- \\
\hline 6 & 1 & 1 & --- & --- & --- & --- & --- & -- & -- & -- \\
\hline 7 & 10 & --- & --- & --- & --- & --- & -- & - & - \\
\hline
\end{tabular}

With the preference data of a potential consumer shown in the Table 4 and the procedure described in this paragraph, expressions (2) and (3), the partial utilities are recalculated. These utilities are presented in Table 5 .

\section{Survey of preferences - de-compositive portion}

To adjust consumers' partial utilities obtained from the composition approach, one utilizes the complete configurations of the products that are presented to consumers for evaluation. In this survey of preferences one has chosen, as seen in the previous section, the comparative evaluation of configurations in pairs. Between 2 product configurations, the potential consumer can choose indifference or one of the configurations. In choosing one of the configurations, the consumer must indicate, in a 3-level scale, how attractive the product is in relation to 
Table 5. Partial utilities of a potential consumer.

\begin{tabular}{|c|c|c|c|c|c|c|c|c|c|c|}
\hline $\begin{array}{l}\text { Attribu- } \\
\text { tes/ levels }\end{array}$ & Mark & $\begin{array}{c}\text { Price } \\
\text { [Reais] }\end{array}$ & $\begin{array}{c}\text { Capacity } \\
\text { [liters] }\end{array}$ & $\begin{array}{c}\text { Heating } \\
\text { control }\end{array}$ & $\begin{array}{c}\text { Timer with } \\
\text { audible } \\
\text { warning }\end{array}$ & $\begin{array}{l}\text { Potency } \\
\text { [Watts] }\end{array}$ & Display & Color & Layout & $\begin{array}{c}\text { Door } \\
\text { opening } \\
\text { [axis] }\end{array}$ \\
\hline 1 & 0.5091 & 0.9091 & 0.0182 & 0.3636 & 0.3636 & 0.0545 & 0.3636 & 0.0273 & 0.0273 & 0.0091 \\
\hline 2 & 0.6364 & 0.7273 & 0.1818 & 0.0364 & 0.0364 & 0.0364 & 0.0364 & 0.2727 & 0.2727 & 0.0909 \\
\hline 3 & 0.3182 & 0.5455 & 0.1273 & --- & --- & 0.5455 & --- & 0.2182 & --- & --- \\
\hline 4 & 0.3182 & 0.3636 & --- & --- & --- & --- & --- & 0.1364 & --- & --- \\
\hline 5 & 0.0636 & 0.1818 & --- & --- & --- & --- & --- & --- & --- & --- \\
\hline 6 & 0.0636 & 0.0909 & --- & --- & --- & --- & --- & --- & --- & --- \\
\hline 7 & 0.6364 & --- & --- & --- & --- & --- & --- & --- & --- & --- \\
\hline
\end{tabular}

the product that has been left aside. Level 1 indicates that a product is slightly more attractive than its competitor, level 2 corresponds to the consumer's certainty that the product is better than its competitor, and level 3 indicates that one of the products is much superior to its competitor.

For keeping the de-compositional portion of measurement coherent with the composition portion, the difference between the utilities of the compared products obeys the following relation: if level 1 is chosen in the comparison, one supposes that the chosen product has utility 0.075 greater than the product left aside; level 2 is equivalent to the difference of 1.25 between the utilities of the products; finally, level 3 is equivalent to the difference of 2.25 between the utilities of the configurations proposed for choice.

The scale suggested in the previous paragraph is adopted because the greatest possible utility of a configuration for a potential consumer is 4 and the smallest one is 0.4 (combinations of the partial utilities of the Table 5). As it is unlikely that between the comparisons between the complete profiles are exactly these configurations, the difference between the utilities of the pairs must always be smaller than 3.6. Admitting that the differences between the utilities of the configurations for the potential consumers of the pairs presented are not close to this extreme, one admits that the greatest difference is of 2.25 .

To justify this choice, consider Figure 5, which illustrates the estimate of distribution of likelihoods between the configurations of the products. In this figure, 1.000.000 of comparisons between configurations has been calculated (from the composition portion of the research with the potential consumers). In Figure 5 one can see that the distribution of the likelihood of occurrence of the differences between the utilities of the configurations has the traditional form of a normal distribution bell. From the data that define the curve of Figure 5, one can calculate estimation for the average and for the standard deviance of the differences between the utilities of the configurations of the products. The estimation of the average (average of sample) is 0.002 [difference units] and the estimation of the standard (standard deviance of sample) is 0.776 [difference units]. That is, as

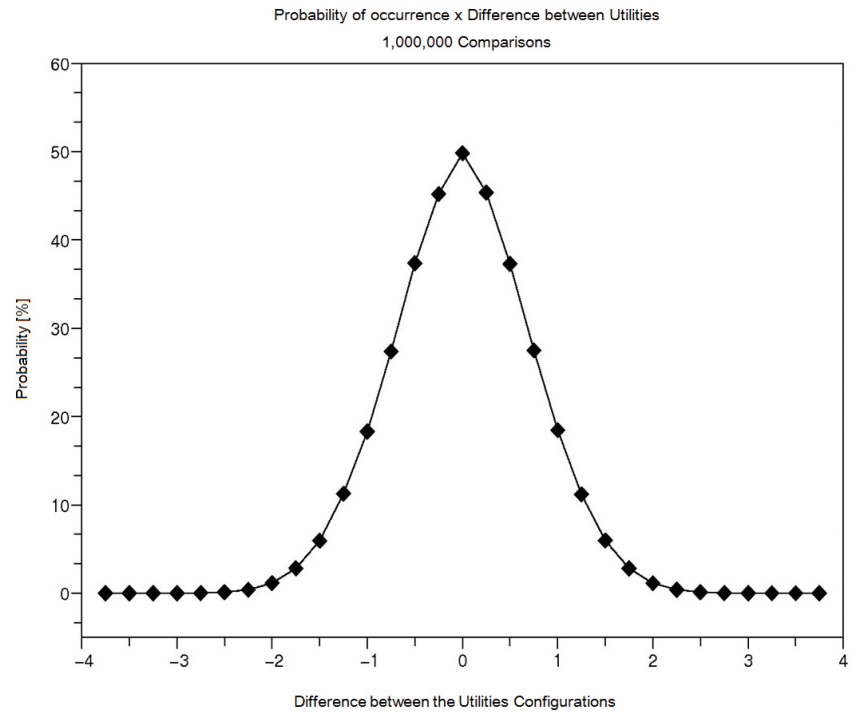

Figure 5. Estimation of distribution of the likelihood of differences between utilities.

the distribution is normal, around $99.7 \%$ of the differences between the utilities of the configurations of the products are between $0.0023(.776)=2.33$ and $0.002+3(.776)=2.33$. Therefore, the scale adopted for the comparison between the complete profile of the products, between 2.25 and 2.25 , covers practically all the possible comparisons. An alternative is to adopt a scale that varies between 1.5 and 1.5 ( 0.5 for each scale increment) admitting coverage of $95 \%$ of the possible differences between utilities of the configurations, in this case one gain a greater resolution to differentiate the configuration alternatives.

\section{Adjustment of the partial utilities}

After being calculated the partial utilities according to the compositive approach, illustrated in Table 5, one can calculate the utilities of any product configuration described by the researched attributes. To adjust the partial utilities obtained with the compositive approach, these measurements are combined with the comparisons 
between the complete profiles of products (de-compositive approach). This adjustment can be carried out by grouping in a matrix the descriptions of the 14 product configurations listed in Table 3 and the comparisons proposed between these same configurations, frame of Figure 1. One forms this matrix by utilizing the concept of dummy variables, that is, for each attribute of the product of a particular configuration only one of the levels will be active (represented with the unit) and the other levels will be inactive (represented by zeros). The first 14 lines of this matrix are defined by the 14 configurations in Table 3, the 7 following lines are defined by the comparisons listed in the frame of Figure 1.

A linear system can be formed by the matrix described in the previous paragraph, by the unknown quantities (a vector of the partial utilities that one wishes to correct), and by the vector composed of the total utilities of the configurations and of the differences of utilities between the compared configurations. The first 14 lines of the vector to the right of the system are the results of the sums of the partial utilities obtained in a composition form present in the configuration of the product defined by the same line of the matrix to the left of the system. The last 7 lines of this vector are the results of the comparison between the complete profiles of products suggested in Figures 6 and 7. The linear system built for the individual's answers, which is being utilized as an example of this procedure of measurement of preferences is presented in Figure 6. The partial corrected utilities can be obtained by applying the method of the minimum squares to the linear system of Figure 6.
The last step suggested for treatment of the data is to displace the vector of the partial utilities of a given individual so that no utility is smaller than 0 and, next, normalize the vector. These two actions are suggested to avoid the appearance of some product configuration with negative utility. When some product presents negative utility, or uselessness, there should be some type of compensation so that the consumer acquires it (for example: discount, payment term, etc.). In spite of the occurrence of products with this characteristic being foreseen, in the complete Joint Analysis they should not occur. The use of negative utilities for product configurations can distort the market share calculation of the products when one utilizes the probabilistic acquisition. But vector normalization is suggested, mainly, for treatment of the configuration problems of the products of greater utility for consumers. In these problems, should normalization not be made, the utility of a product configuration for a researched consumer can be great enough to cover up the low utility of this same configuration for the other consumers.

\section{Interpretations of measurements}

The differences between the directly measured utilities and the utilities corrected by the proposed hybrid procedure, for the individual utilized as an example, can be seen in Table 6. In this frame one shows the importance of each attribute measured by the direct and hybrid method, corrected by the comparison between complete profiles of products via linear system presented in Figure 6, for the preferences of the individual utilized in this example.

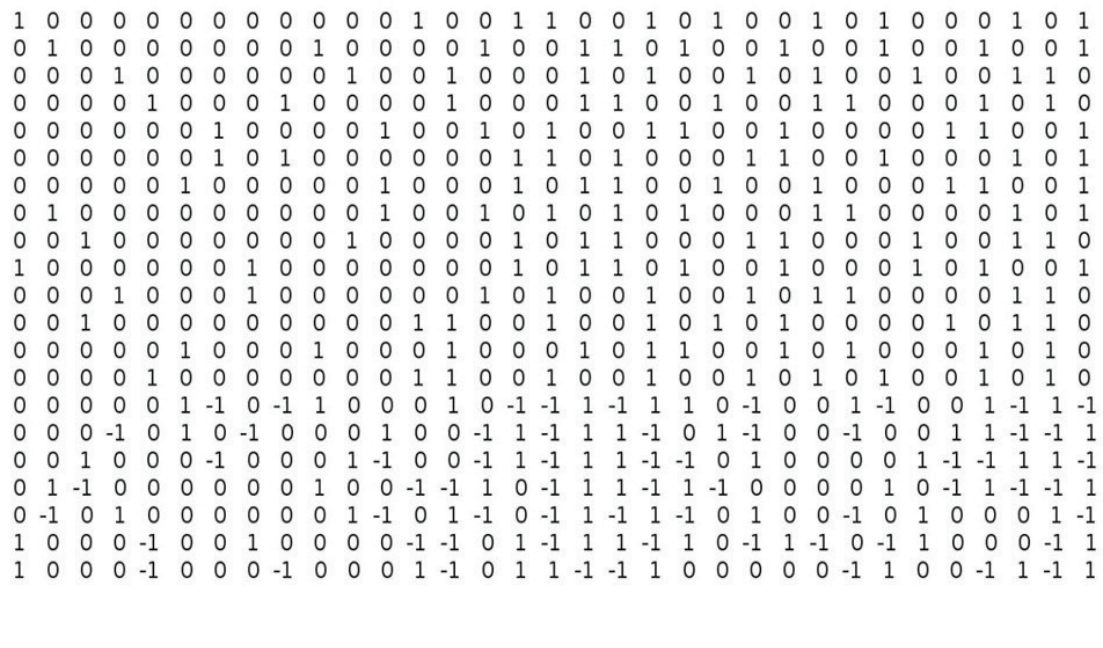

$\begin{array}{lllllllllllllllllllllllllllllllll}1 & 0 & 0 & 0 & 0 & 0 & 0 & 0 & 0 & 0 & 0 & 0 & 1 & 0 & 0 & 1 & 1 & 0 & 0 & 1 & 0 & 1 & 0 & 0 & 1 & 0 & 1 & 0 & 0 & 0 & 1 & 0 & 1\end{array}$

$\begin{array}{lllllllllllllllllllllllllllllllllll}0 & 1 & 0 & 0 & 0 & 0 & 0 & 0 & 0 & 1 & 0 & 0 & 0 & 0 & 1 & 0 & 0 & 1 & 1 & 0 & 1 & 0 & 0 & 1 & 0 & 0 & 1 & 0 & 0 & 1 & 0 & 0 & 1\end{array}$

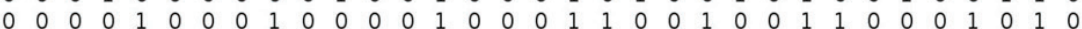

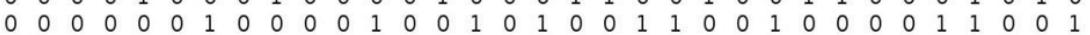

$\begin{array}{lllllllllllllllllllllllllllllllll}0 & 0 & 0 & 0 & 0 & 0 & 1 & 0 & 1 & 0 & 0 & 0 & 0 & 0 & 0 & 1 & 1 & 0 & 1 & 0 & 0 & 0 & 1 & 1 & 0 & 0 & 1 & 0 & 0 & 0 & 1 & 0 & 1\end{array}$

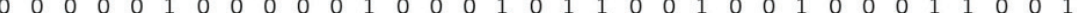

$\begin{array}{lllllllllllllllllllllllllllllllll}0 & 0 & 1 & 0 & 0 & 0 & 0 & 0 & 0 & 0 & 1 & 0 & 0 & 0 & 0 & 1 & 0 & 1 & 1 & 0 & 0 & 0 & 1 & 1 & 0 & 0 & 0 & 1 & 0 & 0 & 1 & 1 & 0\end{array}$

$\begin{array}{llllllllllllllllllllllllllllllllll}1 & 0 & 0 & 0 & 0 & 0 & 0 & 1 & 0 & 0 & 0 & 0 & 0 & 0 & 0 & 1 & 0 & 1 & 1 & 0 & 1 & 0 & 0 & 1 & 0 & 0 & 0 & 1 & 0 & 1 & 0 & 0 & 1\end{array}$

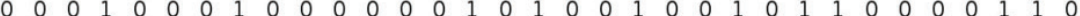

$\begin{array}{lllllllllllllllllllllllllllllllll}0 & 0 & 1 & 0 & 0 & 0 & 0 & 0 & 0 & 0 & 0 & 0 & 1 & 1 & 0 & 0 & 1 & 0 & 0 & 1 & 0 & 1 & 0 & 1 & 0 & 0 & 0 & 0 & 1 & 0 & 1 & 1 & 0 \\ 0 & 0 & 0 & 0 & 0 & 1 & 0 & 0 & 0 & 1 & 0 & 0 & 0 & 1 & 0 & 0 & 0 & 1 & 0 & 1 & 1 & 0 & 0 & 1 & 0 & 1 & 0 & 0 & 0 & 1 & 0 & 1 & 0\end{array}$

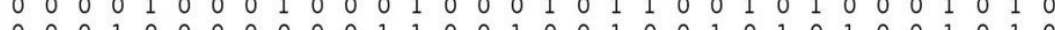

$\begin{array}{lllllllllllllllllllllllllllllllll}0 & 0 & 0 & 0 & 0 & 1 & -1 & 0 & -1 & 1 & 0 & 0 & 0 & 1 & 0 & -1 & -1 & 1 & -1 & 1 & 1 & 0 & -1 & 0 & 0 & 1 & -1 & 0 & 0 & 1 & -1 & 1 & -1\end{array}$

$\begin{array}{lllllllllllllllllllllllllllllllll}0 & 0 & 0 & -1 & 0 & 1 & 0 & -1 & 0 & 0 & 0 & 1 & 0 & 0 & -1 & 1 & -1 & 1 & 1 & -1 & 0 & 1 & -1 & 0 & 0 & -1 & 0 & 0 & 1 & 1 & -1 & -1 & 1\end{array}$

$\begin{array}{lllllllllllllllllllllllllllllll}1 & 0 & 0 & -1 & 0 & 0 & 0 & 1 & -1 & 0 & 0 & -1 & 1 & -1 & 1 & 1 & -1 & -1 & 0 & 1 & 0 & 0 & 0 & 0 & 1 & -1 & -1 & 1 & 1 & -1\end{array}$

$\begin{array}{ccccccccccccccccccccccccccccccccc}0 & -1 & 0 & 1 & 0 & 0 & 0 & 0 & 0 & 0 & 1 & -1 & 0 & 1 & -1 & 0 & -1 & 1 & -1 & 1 & -1 & 0 & 1 & 0 & 0 & -1 & 0 & 1 & 0 & 0 & 0 & 1 & -1\end{array}$

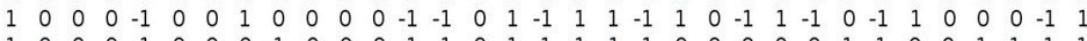

$L$

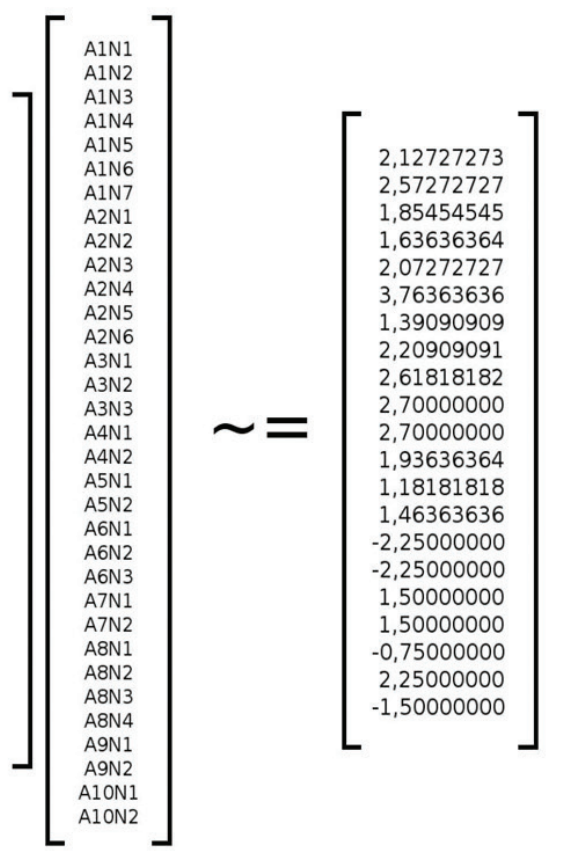

Figure 6. Linear system for adjustment of consumers' preferences. 
Table 6. Comparative form of the attributes, before and after the correction.

\begin{tabular}{|l|c|c|}
\hline \multirow{2}{*}{\multicolumn{1}{c|}{ Attributes }} & \multicolumn{2}{c|}{ Importances [\%] } \\
\cline { 2 - 3 } & Direct & Hibrid \\
\hline Mark & 15.91 & 16.51 \\
\hline Price & 22.73 & 21.25 \\
\hline Capacity & 4.54 & 11.97 \\
\hline Control & 9.09 & 0.23 \\
\hline Timer & 9.09 & 16.57 \\
\hline Potency & 13.64 & 6.28 \\
\hline Display & 9.09 & 13.61 \\
\hline Color & 6.82 & 6.40 \\
\hline Layout & 6.82 & 7.06 \\
\hline Door opening & 2.27 & 0.12 \\
\hline
\end{tabular}

Some utilities measured in a direct form are kept when the potential consumer is submitted to the comparison between complete profiles of products, however, some are significantly altered. Consider, for example, the attribute Door Opening. This attribute, initially, for this particular consumer, presented a relative importance of $2.27 \%$. In adjusting this importance to the information obtained in a de-compositive form, the importance has fallen to $0.12 \%$. For this consumer, in rationally evaluating the alternatives, the door opening turning around a vertical axis was more useful than the door opening around a horizontal axis. In comparing the complete profiles of products presented, this consumer has considered more useful the alternatives with a door opening around a horizontal axis. In adjusting the data obtained in a direct form to the de-compositive information, by compensation, the importance of this attribute has fallen to practically zero (in spite of being already low when directly measured). As the importance of the attributes is comparative, when the importance of this specific attribute falls, after the adjustment, other attributes are corrected. This analysis is valid for all the attributes that have been considered in the description of the products.

\section{Research results}

The procedure for measuring consumers' preferences presented in this paper has been applied to 42 potential consumers of electric mini-ovens. Most of the interviews, around $80 \%$, have been conducted in a collective way, the rest in an individualized manner. On average, the interviews have lasted around 30 minutes. After filling in the forms presented in Figures 2, 3, and 4, the data have been treated according to the procedure described in Sections 6, 7, and 8 of this paper. The partial utilities for the levels of the attributes presented for evaluation are compiled in Figure 7. The first column shows the partial utilities, computed according to the proposed procedure, the choices of the potential consumer utilized as an example along the paper.

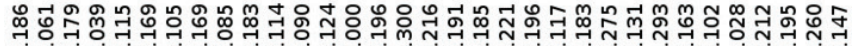

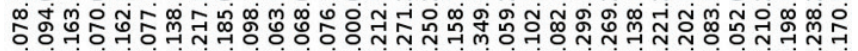

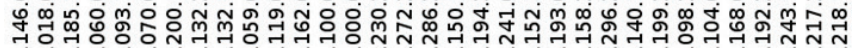
๓

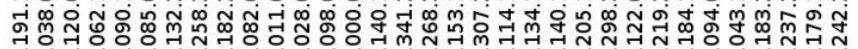

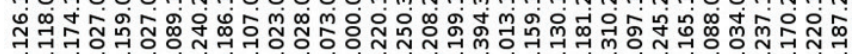

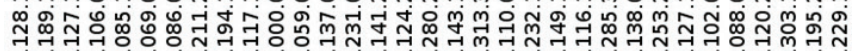

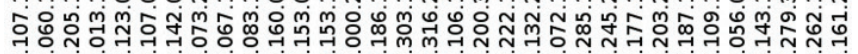

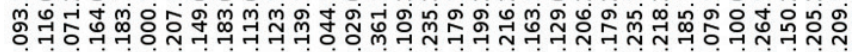

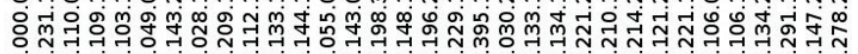

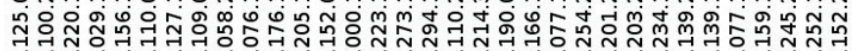

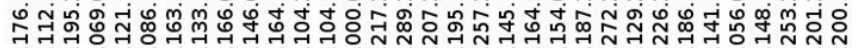

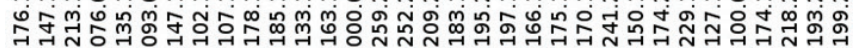

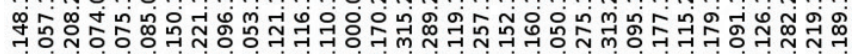

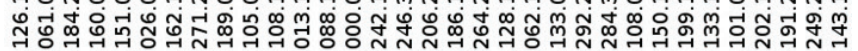

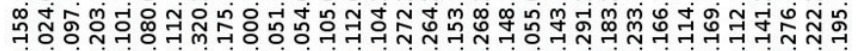

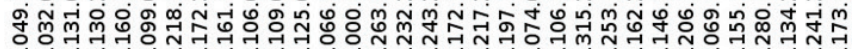

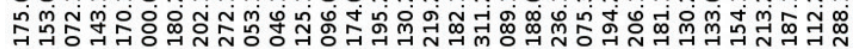

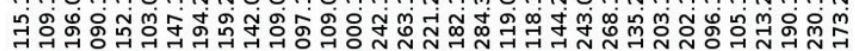

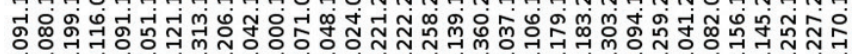

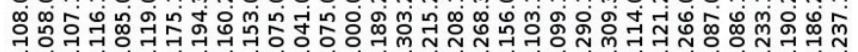

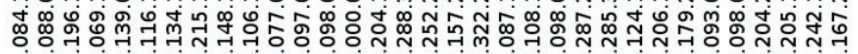

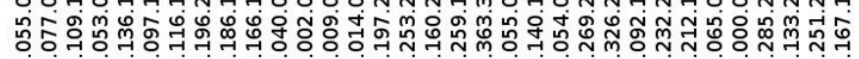

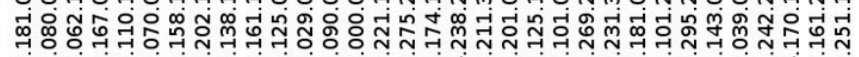

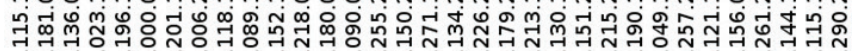

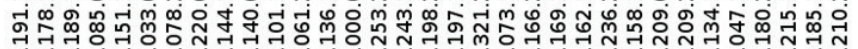

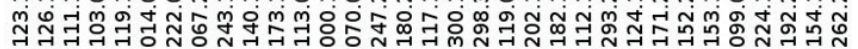

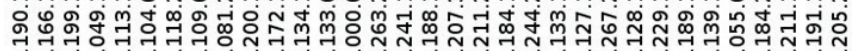

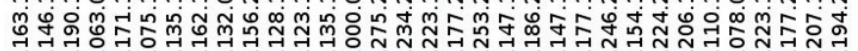

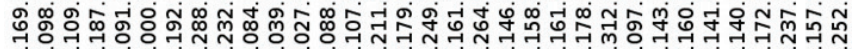

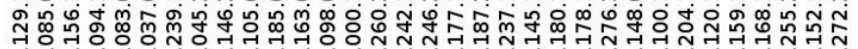

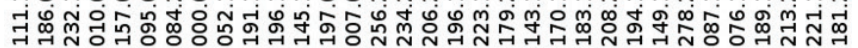

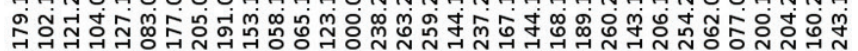

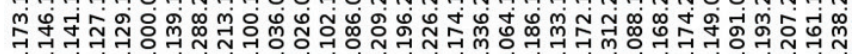

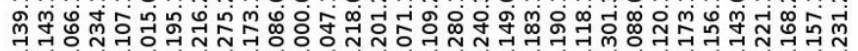

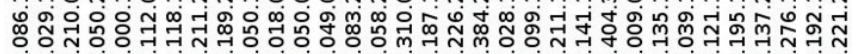

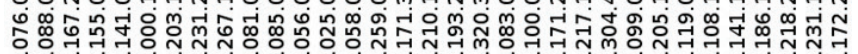

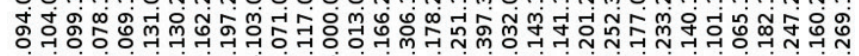

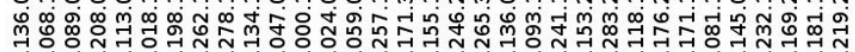

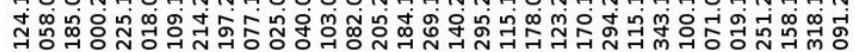

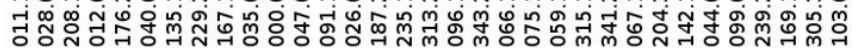

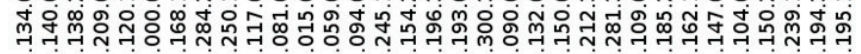

Figure 7. Partial utilities of the 42 interviewees.

These partial utilities are utilized as entry information in the definition process of the configurations of electric mini-ovens.

\section{Importance of the attributes}

The average importances of this group of 42 potential consumers consulted are compiled in Table 7 . In this frame 
Table 7. Comparative frame of the importances of attributes (average consumer).

\begin{tabular}{|c|c|}
\hline Attributes & Importances [\%] \\
\hline Mark & 10.27 \\
\hline Price & 11.18 \\
\hline Capacity & 21.27 \\
\hline Control & 5.34 \\
\hline Timer & 16.66 \\
\hline Potency & 7.22 \\
\hline Display & 15.37 \\
\hline Color & 10.62 \\
\hline Layout & 1.72 \\
\hline Door Opening & 0.35 \\
\hline
\end{tabular}

one can see that the attribute of greater importance, for a consumer with a behavior represented by the average of the 42 researched individuals, is the oven volume, next one has the presence of the display and timer with a sound notice. The next attributes, by order of importance for these consumers, are Mark, price, and color, followed by potency and heating control. Finally, with marginal relative importances, there are layout and door opening axis. It is interesting to notice that, for this 'average' consumer, mark and price are not more important in the purchase decision of an electric mini-oven.

Still considering the behavior of a consumer whose preferences are equal to the average of the researched, it is interesting to notice what the utility is for each of the price levels suggested in the research. Figure 8 illustrates this variation. The behavior of the utility of this particular attribute is close to what is expected: great utility for low prices and high sensitivity for price changes in this range. In the higher ranges of prices utility is low, as well as the sensitivity to price change.

\section{Configuration of the products for maximum utility}

The 'ideal' configuration of an electric mini-oven, from the consumers' perspective, is the one which results in a greater utility for the researched group. According to the information measured, the 'ideal' configuration is of an electric mini-oven of the mark Walita, price of $\mathrm{R} \$ 100.00$, capacity of 9 liters, presence of heating control and timer, 1050 Watts of potency, white, vertical layout, and door opening also vertical. The total utility of this configuration is of 82.02 units of relative utility. When the addition of the attribute display to the product configuration is permitted, the ideal configuration is the same as the previous one, adding the display. The total utility of this configuration between the researched consumers increases from 82.02 to 90.75 units of relative utility.

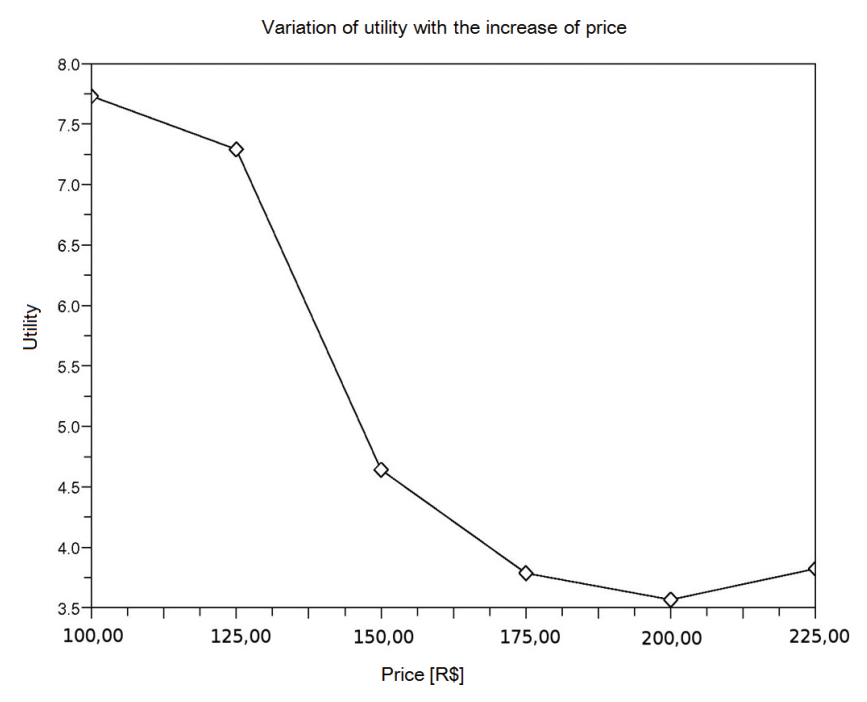

Figure 8. Behavior of utility when prices vary (average consumer).

The ideal configuration of a mini-oven of the mark Hot, from the consumers' standpoint (maximization of utility), must have the price of $\mathrm{R} \$ 100.00$, capacity of 9 liters, presence of heating control and timer, 1050 Watts of potency, display present, white, vertical layout, and door opening also vertical - that is, with the exception of the mark, all the other attributes are equal to those obtained for maximum utility of the products without the mark restriction. The total utility of this configuration between the researched individuals is of 89.58 , close to the maximum utility of 90.75 registered for the same configuration with the mark Walita.

\section{Conclusions}

The measurement of consumers' preferences proposed in this paper is formulated to work around some difficulties found in the application of traditional hybrid approaches. The difficulties found in traditional approaches are the need of computational systems for supporting measurement and the ordination of a set, many times big, of configurations of products. The proposed approach presents similarities and differences with the Hybrid Joint Analysis and with the Adaptative Joint Approach. The compositional portion of measurement is similar to traditional approaches. The de-compositional portion of measurement is based on the comparison of complete product configurations pairs, as well as on the Adaptative Joint Analysis, that is, the researched do not need to ordinate a set of product configuration alternatives (proposed in the Hybrid Joint Analysis). According to the measurement approach suggested, the research form can be built before the start of measurement of consumers' preferences, as well as in the Hybrid Joint Analysis, as opposed to the Adaptative Joint Analysis which defines the product configuration pairs for 
comparison with the course of the research. Due to these particular characteristics of the approach proposed in this paper, one can estimate the partial utilities of the attributes of electric mini-ovens without the use of supporting systems (as computers) and without burdening the interviewees' time. As an example of the use of measurements carried out with the proposed approach, the partial utilities are employed to know the 'ideal' configurations of products for a potential consumer whose preferences are equal to the average of the measured preferences. This product configuration example permits to conclude that, besides measuring consumers' preferences, more sophisticated choice processes must be implemented in conjunction with the measured utilities to accurately define the product configurations with a success potential in the market. The grouping of this information by similarities is an option to the product configuration for market niches. More current options as the employment of evolutive algorithms for the search of the best product configurations (under the most diverse aspects) has shown themselves as an attractive alternative to the treatment of information on consumers' preferences, according to results of recent studies by the authors of this paper.

\section{References}

DOVE, D. W.; BACHELDER, E. L. Matching Product Features with Costumer Needs. Bank Marketing, v. 22, n. 3, p. 3336, 1990.

GREEN, P. E.; SRINIVASSAN, V. Conjoint Analysis in Marketing: New Developments With Implications for
Research and Practice. Journal of Marketing, v. 54, n. 4, p. 3-17,1990. http://dx.doi.org/10.2307/1251756

LAKSHMIKANTHA, K. S. et al. Application of Conjoint Analysis in New Product Development. In: NATIONAL CONFERENCE ON PRODUCT DEVELOPMENT WITH MECHATRONIC SYSTEMS FOR GLOBAL QUALITY, 2005, Madurai. Proceedings... 2005. p. 33-37.

MARKETING ASSOCIATION OF AUSTRALIA AND NEW ZEALAND - MAANZ. Dictionary of Marketing Terms. 2008. Available from: <http://www.marketing.org. au/glossaries.aspx $>$.

MILLER, J. T. et al. Using Tradeoff Analysis to Determine Valueprice Sensitivity of Custom Calling Features. American Business Review, v. 16, n. 1, p. 8-13, 1998.

NAGLE, T. T.; HOLDEN, R. K.; ZALE, J. The Strategy and Tactics of Pricing: A Guide to Growing More Profitably. Prentice Hall, 2006.

SANDS, S.; WARWICK, K. What Product Benefits to Offer to Whom - An Application of Conjoint Segmentation. California Management Review, v. 24, n. 1, p. 6974, 1981. http://dx.doi.org/10.2307/41164944

TESSAROLO, P. Conjoint Analysis Teoria ed Applicazioni, Gestione Aziendale. Dipartimento di Tecnica e Gestioni dei Sistemi Industriali - Università di Padova; 2004.

YAMAMOTO, M.; LAMBERT, D. R. The Impact of Product Aesthetics on the Evaluation of Industrial Products. Journal of Product Innovation Management, v. 11, p. 309324, 1994. http://dx.doi.org/10.1016/0737-6782(94)90086-8 